\title{
Application of Informative Teaching Method in the Practical Training of Tooth Carving
}

\author{
$\mathrm{Na} \mathrm{Li}$ \\ Medical School, Binzhou Vocational College, Binzhou, Shandong Province, China \\ (951011580@qq.com)
}

\begin{abstract}
The design features of tooth carving lessons emphasize the combination of theory and practice. The aim of the teaching such lessons is to promote student's professional and technical ability and ensure the comprehensive development of students on a professional foundation. However, with the deepening of teaching practice, there are still some practical problems in the teaching process of this subject, such as unsatisfactory teaching effect and unclear teaching objectives. Entering the era of information change in the 21 st century, in order to adapt to the trend of teaching development and to effectively improve the teaching effectiveness of specialized courses, this paper analyses the application of informative teaching methods in the course of "practical dental carving", with a view to analyzing the actual teaching effect of information teaching methods, and putting forward some teaching improvement countermeasures.
\end{abstract}

Keywords: "Practical training of teeth carving" course; Informative teaching

\section{Introduction}

The oral medicine technical specialty class includes many courses, among which the practical training of dental carving is a core course of the specialty and a compulsory course for higher vocational students. Students' knowledge and skills are acquired through the classroom learning, so their skills in dental carving depend on the effectiveness of teaching. The teaching process of dental sculpture is characterized by the combination of theory and practice. Therefore, the effectiveness of classroom teaching method is an important guarantee for the course teaching practice to reach the expected goal. The aim of dental sculpture teaching is to promote students' professional skills and ensure their comprehensive development in the basis of their excellent skills. However, there are many deficiencies in the present dental sculpture teaching, which have led to the ineffectiveness of the teaching method of dental sculpture. Therefore, the improvement of the teaching system of dental carving has become the focus of current researchers.

The Present Situation of Teaching and Informative Application in the Course of "Practical Training of Teeth Carving". The curriculum of the practical training of tooth carving is very comprehensive, and it covers a great deal of contents. It is deemed as a professional course that is highly systematic, scientific and practical. The requirements of dental carving course are very strict, so students must equip highly comprehensive quality to master dental carving skills. However, in the practical teaching, many schools fail to realize the characteristics of dental carving classroom teaching correctly, focusing only on the teaching of knowledge and ignoring the importance of ability training. Their curriculum design is not scientific or reasonable. In classroom teaching activities, the role of teachers should be a leader, with students as the main body, to promote students' personality development, but the actual situation is the opposite. Some teachers still 
follow the traditional teaching methods and ignore their students' subjective initiative, which is not conducive to the development of students' independent learning ability and to improve the comprehensive quality of students.

Taking my school as an example, the application and popularization of information technology has gradually contributed to the establishment of the campus network. The course of practical training of tooth carving is taught by the author, so the author investigated the informative teaching level of the practical training of tooth carving course based on the campus network. The course of practical training of dental sculpture is a required course for the technical specialty of oral medicine. Therefore, the author investigated the use of modern information technology by sophomore students in higher vocational school. The results show that there is blindness in the process of searching for the data.

Lack of Autonomy in Learning. With the help of economy and technology, the network has become more and more popular in our life. The network enriches people's lives and can serve different people. But, the network doesn't classify its information to meet the needs of different age groups, leading to an unclear goal in the process of searching for appropriate data.

Lack of Clear Learning Goals. Although students can learn by themselves to a certain extent, the results are not ideal. The training of dental sculpture is influenced by the traditional teaching mode, which makes it difficult to apply the information technology in the teaching of dental sculpture. In the course of the practical training of dental body carving, slides are often involved, but the resources of network teaching are seldom used. In addition, it is difficult for teachers and students to communicate with each other because of the limited teaching conditions.

\section{Construction of Informative Education Mode in the Course of "Practical Training in Dental carving"}

Information technology is the foundation and premise of the construction of informative teaching mode, and space and time are the two main factors that influence information technology. At present, the primary problem that teachers in higher vocational school need to solve is how to change the present situation of students' weak independent learning ability. Improving teaching design is an effective way to mobilize students' learning enthusiasm. The improvement of teaching design can help teachers and students to interact and enhance students' practical ability.

The improvement of teaching design can start from many aspects, for example, in the classroom teaching process, teachers can divide students into groups and instruct them to learn in groups. Teaching tasks can be distributed to every students before the start of the course and discussed within the group by the students themselves, during which the contents of the study are previewed. Finally, the results of the study are reported online to the teachers. Then, the teachers can choose some excellent reports to show them to the whole class through Power Point and ask students to remark on the example after their heated discussion. In this way, the teachers can introduce the main content to students in a natural way. Since all the students have done the preview before the lesson ,they can easily grasp the central information in this class. The classroom discussion method can arouse students' enthusiasm and initiative in learning, making students the subject of classroom learning. It is conducive to the cultivation of students' habit of independent learning. Changing the traditional way of one-way evaluation and combining the feedback from students, teachers and groups will help to add more fun to the teaching process. Students and teachers can interact with each other in finishing homework. It is unavoidable that students may confront some difficulties that can't be solved by themselves, so they can ask their teachers for help through some chatting platforms. The teachers helping students solve homework problems can help students consolidate 
their knowledge. Although there are some differences between the traditional teaching mode and the new teaching mode, the two teaching modes should achieve the same goal from the perspective of their teaching aim. The basic goal is to teach students specialized theoretical knowledge and practical skills. But the new teaching mode(informative teaching mode) is more conducive to the cultivation of students 'practical ability and learning initiative, so it can improve students' learning efficiency.

\section{Countermeasures for the Informative Optimization of Classroom Teaching in the Course of "Practical Training in Dental Carving"}

The paper has analyzed the main problems in the course of teaching and the necessity of constructing informative mode in the course of practical training of dental carving. Several advise have been put forward based on the concrete problems.

Conducting Aesthetic Education in an Informative Way. The so-called dental carving refers to the basic restoration of the mouth. Students should pay attention to the aesthetic feeling of tooth in the process of carving, which requires students to have a high aesthetic appreciation quality and ability. First of all, students should master a solid knowledge of sketch and lay a solid foundation for carving skills. In the daily teaching process, teachers should also pay attention to cultivate students 'aesthetic ability. In the actual teaching process, teachers should emphasize on cultivating students' understanding of space form, regularly carry out courseware display through multimedia, organize students to carry out painting practice, and further develop students' space conversion ability and three-dimensional design thinking through the application of multimedia courseware design display in the painting process. In addition, teachers will gradually enable students to master the ability to measure and adjust body volume relationship through computer applications. So aesthetics is an important part of classroom teaching, and the auxiliary application of informative teaching is the key to improve students' aesthetic appreciation ability.

Strengthening the Training of Mapping. The introduction of the new curriculum reform breaks the traditional classroom teaching pattern and requires teachers to present more distinctive teaching design. In the present dental carving courses in colleges and universities, most of the schools use one or three times as many training methods, but this training mode neglects the training of carving, and it has an adverse impact on the improvement of students 'dental carving skills. There are many outstanding advantages of using computer to describe graphics. Training students' ability of drawing graphics by computer can enhance students' comprehension ability, improve students 'memory level and promote students' spatial imagination ability. Therefore, in classroom teaching teachers should pay attention to the development of students 'ability of drawing, and make computer graphics construction and drawing training as part of classroom teaching. The training can be set before the tooth carving, letting the students figure out the tooth body first through the computer, and then make the tooth carvings according to the drawing plane. Three times the body description method is the fangs commonly used in the usual training, and multi aspect map, shadow map and tooth line graph are the three most common painting methods. Although three times big body drawing enables students to master the tooth carving technology to some extent, it has some limitations, To make it specific, it's time-consuming and difficult. So in practice three times the body drawing training should be strengthened.

\section{Teaching Integration in Informative Way}

The new curriculum reform put forward the quality education, which emphasizes the students' 
subjectivity. Under the influence of the quality education, the primary task of each subject is to realize the integrated development of teaching, tooth carving training is no exception. Realizing teaching integration is to link theory with practice, to give full play to the main role of students, and to mobilize students 'subjective initiative. The realization of teaching integration should start from the curriculum, the teachers should adjust the content of the existing professional teaching through informative means, highlighting the focus and difficulties of the curriculum. Teachers should change the traditional teaching mode and construct various related curriculum activities according to the characteristics of the subject through the network, such as expanding the students 'ability to apply computer graphics painting, regularly arranging the assessment for students, strengthening the comprehensive skills of students in the use of computer graphics, and constantly innovating the content of the curriculum so that classroom teaching schedule can consist with students' wish when studying on the Internet. Teachers are the main force in organizing classroom activities. Every teaching task can not be completed without students' cooperation. Computer operation and informative teaching can effectively help teachers to improve their teaching effectiveness and level. Therefore, expanding regularly computer and network learning plan can effectively ensure the realization of the integration of the teaching in the "tooth carving training" course.

\section{Conclusion}

The traditional teaching mode has certain defects, in that the teacher just teaches the theoretical knowledge to the students and the students accept the knowledge passively. This kind of teaching mode is so rigid that it is not conducive to the students' subjective initiative. Compared with the traditional teaching mode, the model of informative teaching has the outstanding advantages: making students the subject of classroom learning, teachers playing an inducing role in the classroom teaching process and fully mobilizing the initiative and enthusiasm of students. What's more, by encouraging students to use computer after class, students can grasp the specialized knowledge structure of the subject more systematically. In addition, the mode of informative teaching further emphasizes the interaction between teachers and students in the classroom, which can effectively promote the close relationship between them, so that teachers have a comprehensive understanding of students' knowledge acquiring level and correct problems in a timely manner to improve their learning efficiency. The information teaching method not only helps students to learn independently, but also help them to grasp the skill of learning systematically by using computer image and so on, which largely improves students' practical ability and level, exercises their thinking ability, and helps students develop their creative thinking.

\section{References}

[1] Chengdong Yan and Hong Liu. The Use of 3 times and 1 times the Size of Gypsum to Study the Teaching Effect of Practical Teaching[ J] . Journal of Qiqihar Medical School, 2014(20): 3057-3058.

[2] Xiaoli Ma, Yali Luo, Lindeng Weng. Application of Formative Evaluation in Practical Teaching of Dental Sculpture[ J] Health Vocational Education, 2012, 32(18): 126-127.

[3] Chunjing Huang, Jianhua Zhang, Shuangyi Wang. Promotion of Natural Dental Carving Training to Improve Students' Dental Carving Level[ J]. General Oral Medicine Electronic Journal, 2016, 3(12): 47-49. 